OPEN ACCESS

Edited by:

Undurti Narasimha Das,

UND Life Sciences, USA

Reviewed by:

Rade Vukovic,

Mother and Child Health Care

Institute of Serbia, Serbia

Priyanka Agarwal,

Cedars-Sinai Medical Center, USA

*Correspondence:

Haroon Khan

hkdr2006@gmail.com

Specialty section: This article was submitted to

Diabetes,

a section of the journal

Frontiers in Endocrinology

Received: 08 August 2016 Accepted: 23 November 2016

Published: 19 December 2016

Citation:

Zafar M, Khan H, Rauf A, Khan A and Lodhi MA (2016) In Silico Study

of Alkaloids as $\alpha$-Glucosidase

Inhibitors: Hope for the Discovery

of Effective Lead Compounds.

Front. Endocrinol. 7:153.

doi: 10.3389/fendo.2016.00153

\section{In Silico Study of Alkaloids as $\alpha$-Glucosidase Inhibitors: Hope for the Discovery of Effective Lead Compounds}

\author{
Muhammad Zafar', Haroon Khan ${ }^{1 *}$, Abdur Rauf ${ }^{2}$, Ajmal Khan $^{3}$ and Muhammad Arif Lodhi' \\ ${ }^{1}$ Department of Pharmacy, Abdul Wali Khan University, Mardan, Pakistan, ${ }^{2}$ Department of Chemistry, University of Swabi, \\ Swabi, Pakistan, ${ }^{3}$ Department of Chemistry, COMSATS Institute of Information Technology, Abbottabad, Pakistan, \\ ${ }^{4}$ Department of Biochemistry, Abdul Wali Khan University, Mardan, Pakistan
}

$\alpha$-Glucosidase (extinction coefficient 3.2.1.20) is a primary carbohydrate metabolizing enzyme that acts on the 1-4 associated $\alpha$-glucose residues. The inhibition of $\alpha$-glucosidase slows down the process of carbohydrate digestion and avoids postprandial hyperglycemia, which is a major cause of chronic diabetes-associated complication. This study was designed to evaluate the binding capacity of isolated alkaloids with targeted receptor. For this purpose, the three-dimensional tertiary structure of the $\alpha$-glucosidase was generated by using the Molecular Operating Environment (MOE). The generated model was then validated by using the RAMPAGE and ERRAT server. The molecular docking of 37 alkaloids along with standard acarbose and miglitol reported as a $\alpha$-glucosidase inhibitor was performed via MOE-Dock implemented in MOE software to find the binding modes of these inhibitors. The results showed that compound $\mathbf{1 7}$ (oriciacridone F) and $\mathbf{2 4}$ (O-methylmahanine) demonstrated marked interaction with active residues and were comparable to standard inhibitors. In short, this study provided computational background to the reported $\alpha$-glucosidase inhibitors and thus further detail studies could lead to novel effective compounds.

\section{Keywords: $\alpha$-glucosidase inhibitors, homology modeling, molecular docking, Molecular Operating Environment, $\alpha$-glucosidase}

\section{INTRODUCTION}

$\alpha$-Glucosidase is a primary carbohydrate digestive enzyme, which is present in the brush border of the small intestine. It has action on 1,4- $\alpha$ bonds and thus different from $\beta$-glucosidase $(1-4)^{1}$. $\alpha$-Glucosidase catalyzes starch and disaccharides to glucose. Maltase is a similar enzyme that acts upon maltose and is nearly equivalent in function to $\alpha$-glucosidase. The carbohydrates need metabolism by $\alpha$-glucosidase before being absorbed into the small intestine. By inhibiting the $\alpha$-glucosidase, the process of carbohydrate digestion slows down, which helps prevent postprandial hyperglycemia because postprandial hyperglycemia is a major cause of chronic diabetes and associated complications (5). In this regard, several research groups have been working on the desiging of new effective $\alpha$-glucosidase inhibitors that can be used as therapeutic agents for the suppression of metabolic disorders such as hyperglycemia, obesity, and non-insulin-dependent type II diabetes mellitus (5).

\footnotetext{
${ }^{1}$ http://www.bioplek.org/animaties/enzymen/maltase2.html.
} 
The therapeutic potential of alkaloids has been recognized in the treatment of various human disorders (6-11). The literature review revealed that approximately 37 isolated alkaloids have been tested for $\alpha$-glucosidase inhibitory activity (12), as shown in Table 1. Gao and colleagues isolated two compounds 1-2 from the leaves of Adhatoda vasica Nees. Both these compounds caused marked competitive $\alpha$-glucosidase inhibition in animal models (13). The phytochemical studies of Campanulaceae

TABLE 1 | The structure of the isolated alkaloids with docking scores.

S. No.

1

Structures
Docking score(s)

$-6.5918$

(S)-1,2,3,9-tetrahydropyrrolo[2,1-b]quinazolin-3-ol

$$
2
$$<smiles>Oc1ccc2c(c1)CN1CC[C@H](O)C1=N2</smiles>

(S)-1,2,3,9-tetrahydropyrrolo[2,1-

$b$ ]quinazoline-3,7-diol

3<smiles>OCC1NC(COC2OC(CO)C(O)C(O)C2O)C(O)C(O)C1O</smiles>

2-(hydroxymethyl)-6-(((3,4,5-trihydroxy-6-

(hydroxymethyl)tetrahydro- $2 H$-pyran-2-

yl)oxy)methyl)piperidine-3,4,5-triol

4<smiles>CCC1NC(CC)C(O)C(O)C1O</smiles>

\section{2,6-diethylpiperidine-3,4,5-triol}

5<smiles>CCC1NC(C)C(O)C(O)C1O</smiles>

2-ethyl-6-methylpiperidine-3,4,5-triol

6<smiles>CCC1CC(O)C(O)C(CO)N1</smiles>

6-ethyl-2-(hydroxymethyl)piperidine-3,4-diol 
TABLE 1 | Continued

S. No.

Structures

Docking score(s)

7<smiles>CCCCC1NC(CO)C(O)C(O)C1O</smiles>

2-butyl-6-(hydroxymethyl)piperidine-3,4,5-triol

8<smiles>CCC1NC(COC2OC(CO)C(O)C(O)C2O)C(O)C(O)C1O</smiles>

2-ethyl-6-(((3,4,5-trihydroxy-6-

(hydroxymethyl)tetrahydro-2H-pyran-2-

yl)oxy)methyl)piperidine-3,4,5-triol

9<smiles>CCC1CC(O)C(O)C(COC2OC(CO)C(O)C(O)C2O)N1</smiles>

2-((6-ethyl-3,4-dihydroxypiperidin-2-yl)methoxy)-6-(hydroxymethyl)tetrahydro-2Hpyran-3,4,5-triol

10<smiles>CC[C@]1(CO)NCC[C@@H](O)[C@@H]1O</smiles>

(2S,3R,4R)-2-ethyl-2-(hydroxymethyl)piperidine-3,4-diol

11<smiles>OCC1NCC(O)C(O)C1O</smiles>

2-(hydroxymethyl)piperidine-3,4,5-triol

12<smiles>OCC1NC(CO)C(O)C1O</smiles>

2,5-bis(hydroxymethyl)pyrrolidine-3,4-diol 
TABLE 1 | Continued

S. No.

13

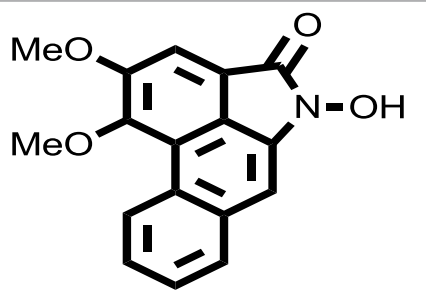

5-hydroxy-1,2-

dimethoxydibenzo[cd,f]indol-4(5H)-one

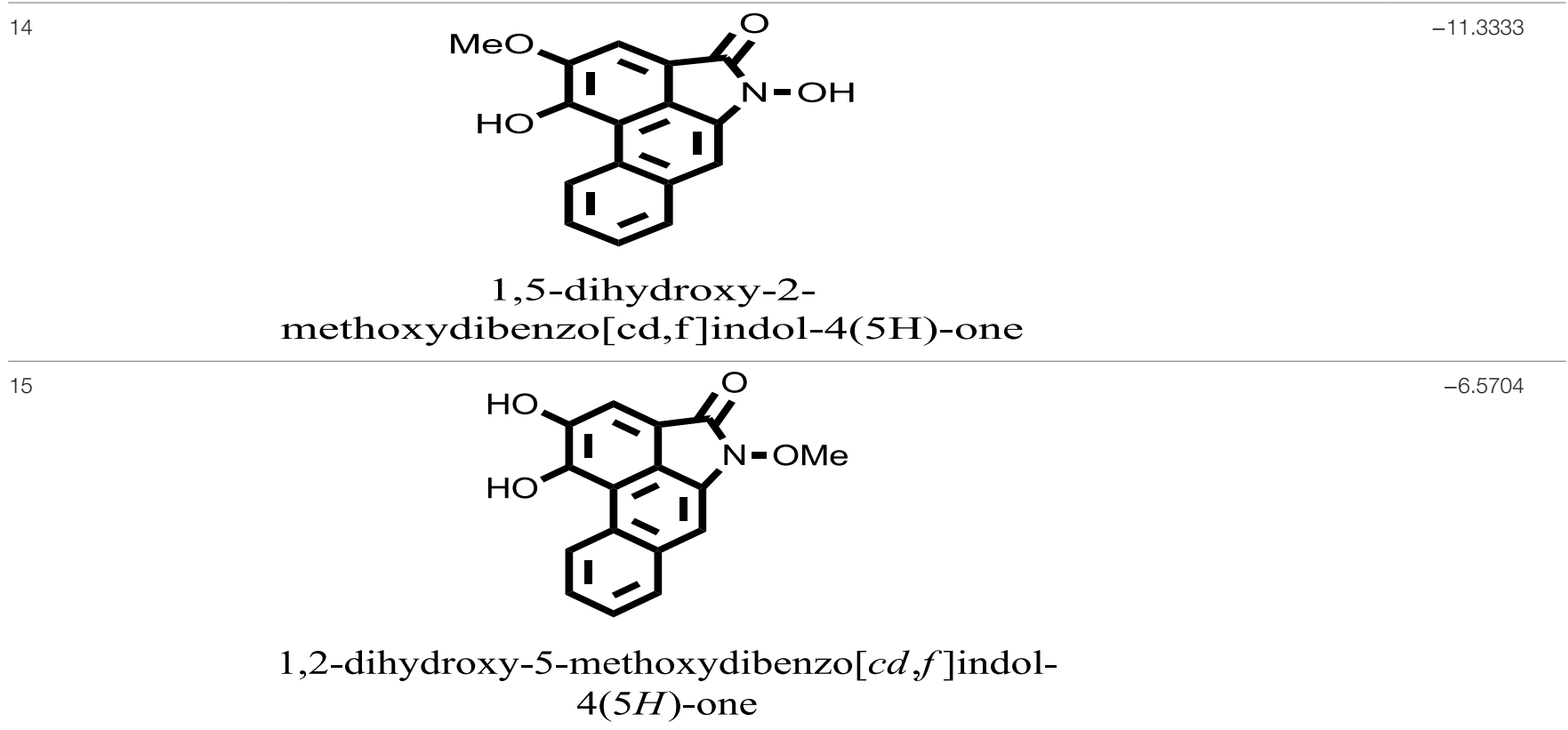

16<smiles>C=C(C)C1Cc2c(cc(O)c3c(=O)c4cccc(O)c4[nH]c23)O1</smiles>

5,10-dihydroxy-2-(prop-1-en-2-yl)-1,2-dihydrofuro[2,3c]acridin-6(11H)-one

17

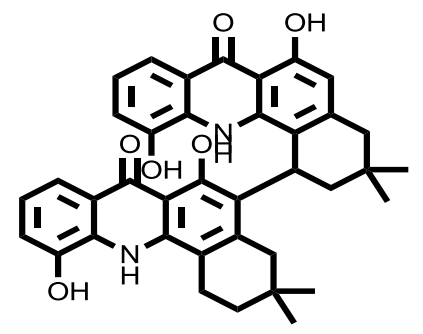

$6,6 ', 11,11^{\prime}$-tetrahydroxy-3,3,3',3'-tetramethyl-

$1,1^{\prime}, 2,2^{\prime}, 3,3^{\prime}, 4,4^{\prime}$-octahydro-[1,5'-bibenzo[c]acridine]-

$7,7^{\prime}\left(12 H, 12^{\prime} H\right)$-dione

Docking score(s) 
TABLE $1 \mid$ Continued

S. No.

Structures

Docking score(s)

18

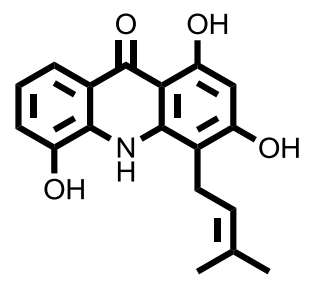

1,3,5-trihydroxy-4-(3-methylbut-2-en-1-yl)acridin-9(10H)-

$$
\text { one }
$$

19

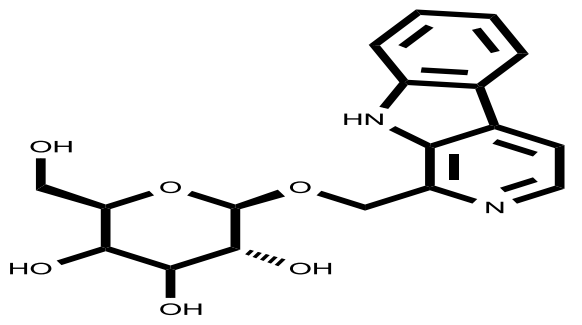

(2R, 3R, 6R)-2-((9H-pyrido[3, 4-b]indol-1-

y1)methoxy)-6-(hydroxymethyl)tetrahydro- $2 \mathrm{H}-$ pyran-3,4,5-triol

20<smiles>O=C1C=C[C@H](O)N1C(=O)CCc1ccccc1</smiles>

(S)-5-hydroxy-1-(3-phenylpropanoyl)-1Hpyrrol-2(5H)-one

21<smiles>CO[C@H]1C=CC(=O)N1C(=O)CCc1ccccc1</smiles>

(S)-5-methoxy-1-(3-phenylpropanoyl)-1H-

pyrrol-2 $(5 H)$-one

22

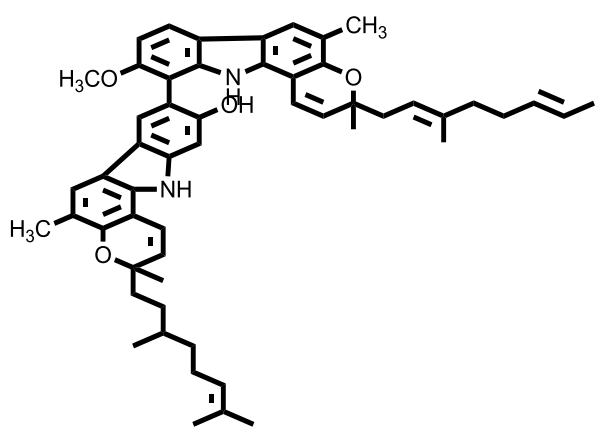

3-(3,7-dimethyloct-6-en-1-yl)-9'-methoxy-3,3',5,5'-tetramethyl-

3'-((2E,6E)-3-methylocta-2,6-dien-1-yl)-3,3',11,11'-tetrahydro-

$\left[8,10^{\prime}\right.$-bipyrano[3,2-a]carbazol]-9-ol 
TABLE 1 | Continued

S. No.

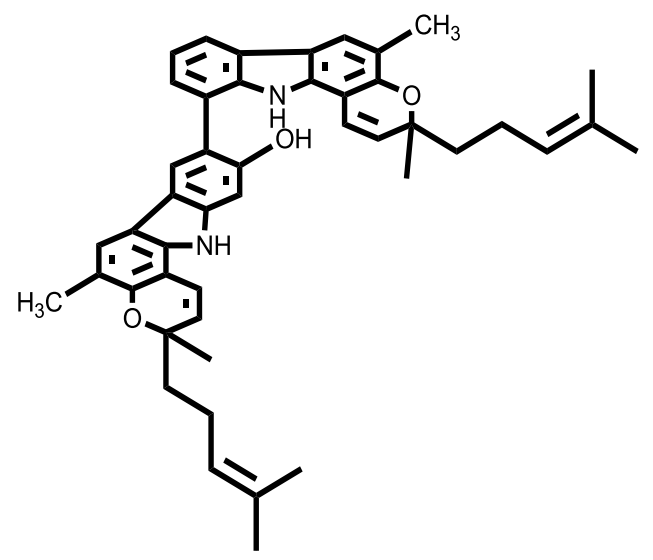

3,3',5,5'-tetramethyl-3,3'-bis(4-methylpent-3-en-1-yl)-3,3',11,11'-tetrahydro-[8,10'-bipyrano[3,2a]carbazol]-9-ol

24

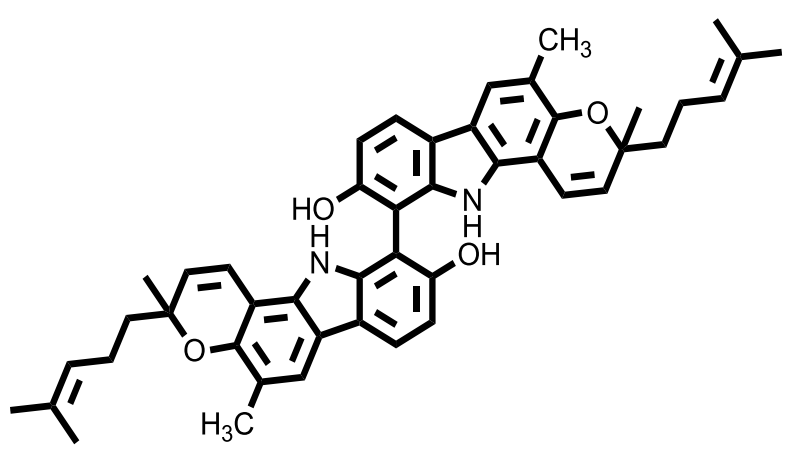

$-14.9192$

3,3',5,5'-tetramethyl-3,3'-bis(4-methylpent-3-en-1-yl)-

3,3 ',11,11'-tetrahydro-[10,10'-bipyrano[3,2-

a]carbazole]-9,9'-diol

25

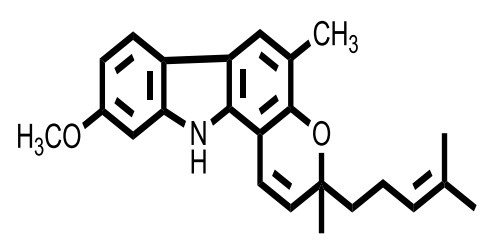

$-10.1657$

9-methoxy-3,5-dimethyl-3-(4-methylpent-3-en-1-yl)-3,11-dihydropyrano[3,2-a]carbazole

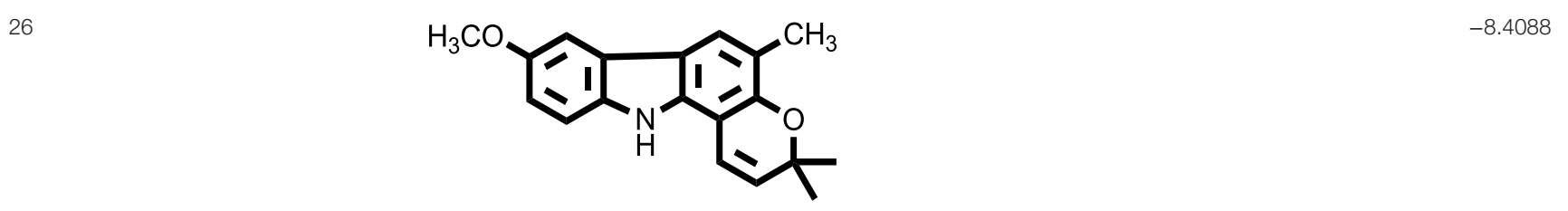

8-methoxy-3,3,5-trimethyl-3,11-dihydropyrano[3,2-a]carbazole 
TABLE 1 | Continued

S. No.

27

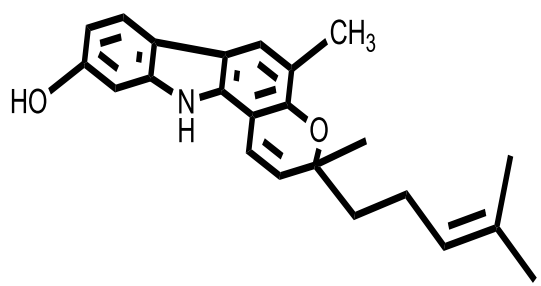

Docking score(s)

$-10.4082$

3,5-dimethyl-3-(4-methylpent-3-en-1-yl)-3,11-dihydropyrano[3,2-a]carbazol-9-ol

28<smiles>COC1=C(O)C(=O)N(C)C1=O</smiles>

$-6.2268$

3-hydroxy-4-methoxy-1-methyl-1H-pyrrole-2,5-dione

29<smiles>COC1=C(C2=C(OC)C(=O)N(C)C2=O)C(=O)N(C)C1=O</smiles>

4,4'-dimethoxy-1,1'-dimethyl-1H,1'H-[3,3'-bipyrrole]-2,2',5,5'-tetraone

30<smiles>COC1=C(C2(O)C(OC)=C(Cl)C(=O)N2C)C(=O)N(C)C1=O</smiles>

2-hydroxy-3,4'-dimethoxy-1,1'-dimethyl-2',5,5'-trioxo-2,2',5,5'-tetrahydro- $1 H, 1$ ' $H$-[2,3'bipyrrol]-4-yl hypochlorite

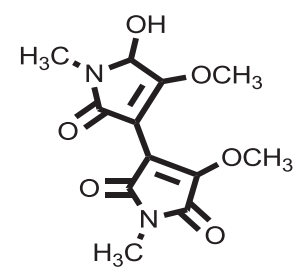

5'-hydroxy-4,4'-dimethoxy-1,1'-dimethyl-1 $H, 1^{\prime} H$-[3,3'-bipyrrole]-2,2',5(5'H)-trione 
TABLE 1 | Continued

S. No

32<smiles>OCC1NCC(O)C(O)C1O</smiles>

Docking score(s)

$-9.5179$

2-(hydroxymethyl)piperidine-3,4,5-triol

33<smiles>OC[C@H]1NCC[C@H](O)[C@@H]1O</smiles>

(2R,3R,4R)-2-(hydroxymethyl)piperidine-3,4-diol

34<smiles>Nc1ccn([C@@H]2O[C@H](CO)[C@@H](O)[C@H]2O)c(=O)n1</smiles>

4-amino-1-((2S,3R,4S,5R)-3,4-dihydroxy-

5-(hydroxymethyl)tetrahydrof uran-2-

yl)pyrimidin-2(1H)-one<smiles>OCC(O)C(O)Cc1cncc(C(O)C(O)C(O)CO)n1</smiles>

1-(6-(2,3,4-trihydroxybutyl)pyrazin-2-yl)butane-1,2,3,4-tetraol<smiles>OCC(O)C(O)Cc1cccc(C(O)C(O)C(O)CO)c1</smiles>

1-(3-(2,3,4-trihydroxybutyl)phenyl)butane-1,2,3,4-tetraol 
TABLE 1 | Continued

S. No. Structures

\section{1,1'-(1,4-phenylene)bis(butane-1,2,3,4-tetraol)}<smiles>OCCN1C[C@H](O)[C@@H](O)[C@H](O)[C@H]1CO</smiles>

Miglitol

Standard

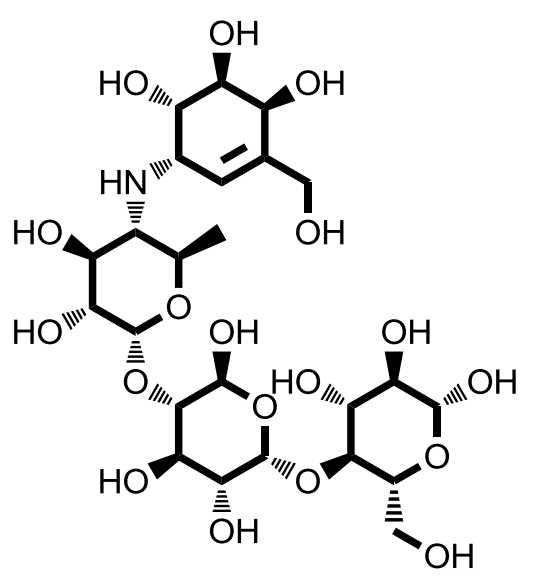

\section{Acarbose}

Lobelia species led to the isolation of 10 compounds 4-12. These compounds also possessed significant anti-glucosidase effect (14). The potent inhibitors, deoxynojirimycin (DNJ) and 2,5-bis(hydroxymethyl)-3,4-dihydroxypyrrolidine (DMDP) (14-18), were isolated from many plants. The DNJ, along with several other therapeutic effects, provoked outstanding attenuation on glucosidase and thus clinically used as a zero-harm-antidiabetic drug agent. Three more alkaloids named piperumbellactams A-C 13-15 have been isolated from Piper umbellatum, produced significant $\alpha$-glucosidase inhibition (19). Wansi et al. isolated acridones alkaloids 16-18, from Oriciopsis glaberrima Engl, also displayed profound $\alpha$-glucosidase inhibition, especially compound $\mathbf{1 7}$ (oriciacridone F) with $\mathrm{IC}_{50}: 34.05 \mathrm{mM}$ (20). Buthus martensii Karsch led to the isolation of 19, a potent non-competitive glucosidase inhibitor (21). Similarly, Piper sarmentosum led to the purification of two chaplupyrrolidones alkaloids A 20 and B 21, which possessed strong anti-glucosidase activity (22). Murraya koenigii guide to the isolation of six different alkaloids 22-27 that caused $\alpha$-glucosidase inhibition. Of the compounds, 


\footnotetext{
CLUSTAL multiple sequence alignment by MUSCLE (3.8)

SP 1 Q $066251 \mathrm{GDE}$ YEAST SPI PS3051 MAIX3_YEAST SP 1 QO6625 IGDE YEAST
SP I PS3051 MAIX3_YEASI SP $12066251 \mathrm{GDE}$ YEAST SPIPS3051 IMAIX了_YEAST SP 1 Q 066251 GDE YEAST SPIP53051।MAIX'3_YEASI SP I RO6625 IGDE YEAST
SPI PS3051 I MAIX3_YEASI Sp 1 Q06625 IGDE YEAST
SP I P53051 IMAIX3_YEASI SP $18066251 \mathrm{GDE}$ YEAST SPIPS3051 IMAIX 3 _YEASI SP 1 Q066251 GDE YEAST

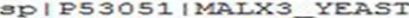
3D 1 Q06625 I GDE YEAST
3P I P53051 I MAIX3 YEASI SP $12066251 \mathrm{GDE}$ YEAST sp I P53051 IMAIX3_YEAST SP I RO6625 I GDE YEAST
3PI P53051 I MAIX 3 YYEASI SP 12066251 GDE YEAST SDI006625।GDE YEAST SP 18066251 GDE YEAST
SP I PS3051 I MAIX3_YEAST SP 19066251 GDE YEAST Sp I 0066251 GDE YEAST SP 1 QO 66251 GDE YEAST
SPI P53051 I MAIX3_YEASI SP 1 Q06625 I GDE YEAST SPIPS3051 IMAIX' 3 _YEAST Sp I Q06625 I GDE YEAST
SP I P53051 I MAIX 3_YEASI Sp 1 Q06625 IGDE YEAST
3PIP53051 IMAIX3_YEAST

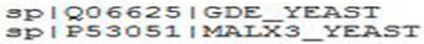
Sp I 906625 I GDE YEAST
3P I P53051 I MAIX3_YEAST 3p I Q06625 IGDE YEAST
3PI 553051 IMAIX3_YEAST 3P| 806625 |GDE YEAST SPI P53051 IMAIX了_YEAST 3P|Q06625।GDE YEAST SPIP53051 IMAIX了_YEAST SP|Q06625/GDE YEAST SPIP53051 IMALX SPIQ06625/GDE YEAST SPI P53051 IMALX 3 Y YEAST

MNRSLILRISDIGEPIISCSYGKGVIIIPPIPLPKDAPFDRPIYIVKLIVSAGSPVARDG

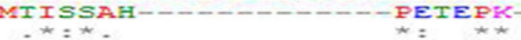

LVWINCPPDHNIP FKRDKFYKCIIHSSFHEDDCIDINVYAPGSYCFYISFRNDNERCEII

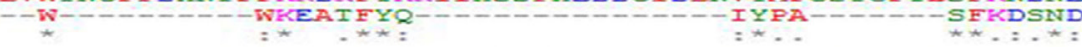
RECYYFVAIFMIYINDQFLPINSIAIQSVVSKWLGSDWEPIISKIAAKNYNMVHFIPIQER

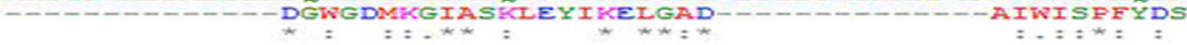

GESNSPYSIYDQLQEDQ--EHFKSPEDVRONLVEHIHRDINMISIIDIVENHIANNSPJIV PQDDMGYDIAN-- YERVWPIYGINEDCFAIIERIHK-IGMMFIIDIVINHCSSEHEWFK

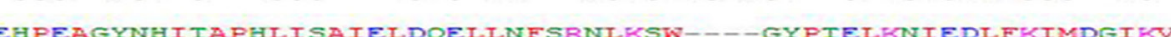
RR DWFFWR PRKGYDAEGKPIPP----

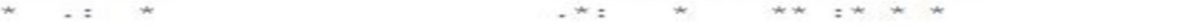
HVIGSIKLWEYYAVNVQTAIRDIKAHWNDESNESYSFPENIKDISSDFVKLASFVRDNVI

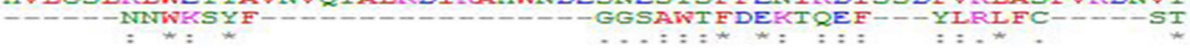
EPNFGILGERNSNRINVPKFIQILKIINDGGSDDSESSIATAQNILNEVNLPLYREYDDD

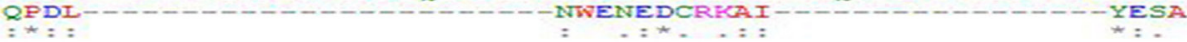
VSEILEQIFNRIKYLRIDDGGPKQGPVIVDVPLIEPYFIRFKGKDGIDYAIANNGWIWNG VGYWIDH--OVDGFRIDVG-OFI NPIVDFASQNSRAYIRREVIVWGDCVRLRYGKSPEDSPYIWERMSKYIEMNAKIFDGFRI FVVDRONST-D DNCHSTPIHVGEYFIDLARKYNPNIYVVAEIFSGSEIIDCLFVERIGISSIIREAMQAWS $\begin{aligned} \text { HEFHQE-D-D- } & \text {. }\end{aligned}$

EEEISRIVHRHGGRPIGSYKFVPMDDFSYPADININEEHCFNDSNDNSIRCVSEIMIPKI

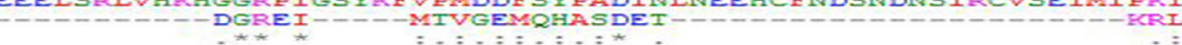
LTATPPHAIFMDCIHDNEIPFERRTVEDIIPNAALVALCSSAIGSVYGYDEIFPHLINLV YISASRHEL IERRHYDISIPIGSPSIGIIRVRAIINSIRISIGERAYDIEDSEMHVHHQGQYIIFHRMD TERTINIAIAEIFRYI-D-

VKSGKGWYLI ARMKFSDNDDPNEILPPVVINQSICSIRFSYALERVGDEIPNDDKFIKKGI NGIDCW
$;.$ PIKLKELEGFDISYDDSKKISIIRIPNEFPQGSIAIFETQQNGVDESIDHFIRSGAIRAT * $:=: *$. SSIIIESINSVIYRSEPEEYDVSAGEGGAYIIPNFGKPVYCGIQGWVSVIREIVFYNDIA 作

HPISANIRNGHWALDYIISRINYYSDEAGINEVQNWLRSREDRVRKCPSYLVPSYFAIII EIRNNYNAIK- D - EEHGENS-D-

GIIYGCCRIKAIOLMSRNIGKSIIFVQSLSMISI QMVSRMKSISIIPGENVPSMAAGIPH IEAIAIISRDHARIPMQFSVNYMRCWGRDVFISLRGMIIIIGRFDEAKAHIIAFAKIIKHGIIPNIIDAGRNPRYNA FSWNYIRCWGRDVFISIRGMILIIGRF DEARAHIIAFARIIEHGLIPINILDAGRIFRYNA RDAAWFFLQAVQDYVYIVPDGEKILQEQVIRRFPIDDTYI PVDDPRAFSYSSILEEIIYE

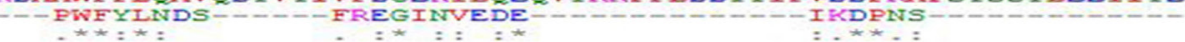
IISRHAKGIKFREANAGPNIDRVMI DKGFNVEI HVDWSIGLIHGGSQYNCGIWMDEOMES VINFWKEAIRERKAH EKAGSVGI PGI PRDGAAIEINGLIKSAIRFVIELRCNKGLFKFSDVEIQDGGRIDFIEWNQ

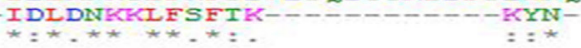
LIQDNFEKRYYVPEDPSQDA-DYDVSAKLGVNRRGIYRDLYKSGKPYEDYQLRPNFAIAM $-0-1$ NKIIFAAINFSSDATDFKIIVAPEIFVPEHAIKAIIIADEVLRGPVGMRILDPSDYNYRPYYNNGEDSDDFATSKGRNY

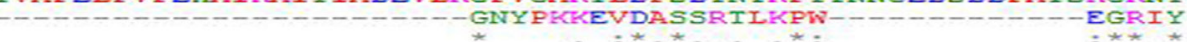
HQGPEWVWLYGYFLRAFHHFHFKISPRCQNAARERPSSYLYQQLYYRIKGHRKWIFESVW (1) AGLIELINRDGEVCNDSSPIQAWSSACLLDLFYDLWDAYEDDS $=: t$
}

FIGURE 1 | Target-template alignment by multiple sequence alignment server. 
O-methylmahanine 24 showed marked effect with $\mathrm{IC}_{50} 29.1 \mu \mathrm{M}$ (23). Tabussum and co-worker isolated plicatanins A-D 28-31 alkaloids from Chrozophora plicata also caused significant $\alpha$-glucosidase inhibition (24). Six alkaloids 32-36 with potent $\alpha$-glucosidase inhibitory activity have been isolated from Morus atropurpurea (12).

The aim of this research study was to find out the interaction of these reported alkaloids with the target protein and thus findings could be useful for the discovery of new, potent, and active $\alpha$-glucosidase inhibitors.

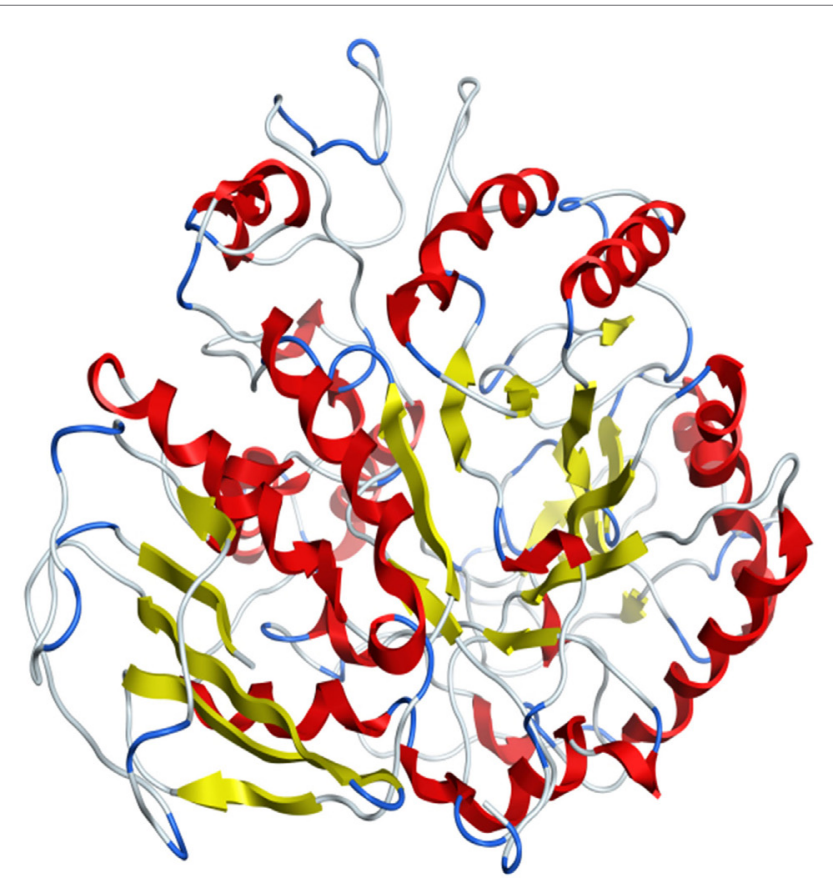

FIGURE 2 | 3D tertiary structure of target.

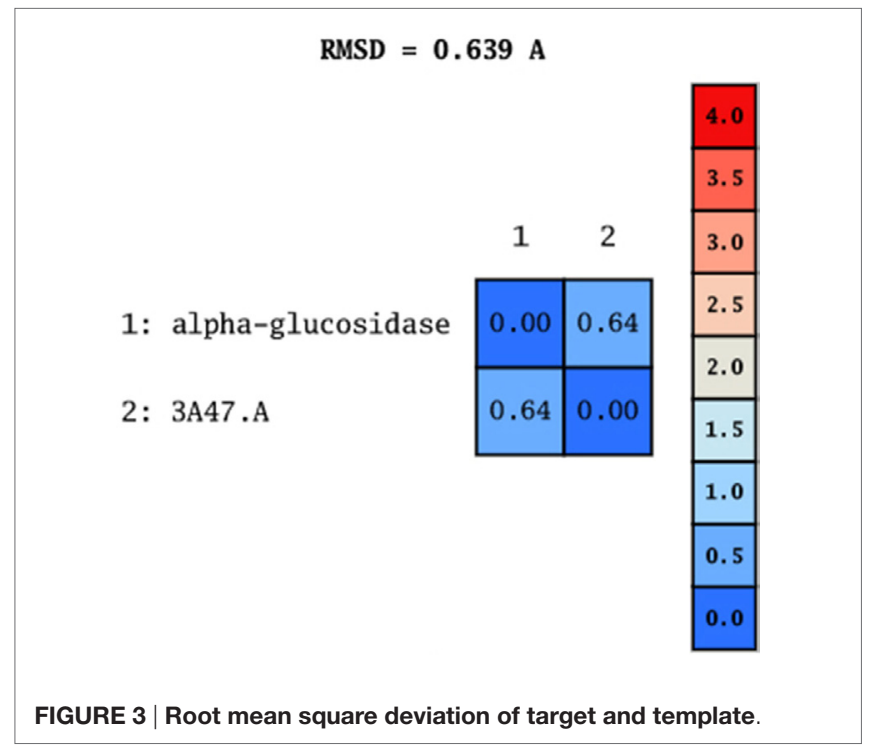

\section{MATERIALS AND METHODS}

In this research studies, we have generated the three-dimensional structure of the glucosidase by using the Molecular Operating Environment (MOE) software, and molecular docking study was performed on the same software. The MOE-Dock was used as docking software implemented in MOE, and ligplot is implemented in MOE for the purpose to visualize the interaction between protein and ligand.

\section{Retrieval of the Target Sequence}

The primary sequence of the $\alpha$-glucosidase of Saccharomyces cerevisiae (Baker's yeast) was retrieved using Uniprot (Universal Protein Resource $)^{2}$ in FASTAformat, and the target sequence was then kept in the text file for further evaluation. The accession number of $\alpha$-glucosidase of $S$. cerevisiae is P07265.

\section{Template Selection}

The target sequence of $\alpha$-glucosidase was downloaded from the Universal Protein Resource (uniprot dataset). Then, ProteinBLAST (25) was done to identify homologs in the PDB (RCSB Protein Databank) (26). Hence, the crystal structure of Isomaltase from the S. cerevisiae (Pdb Id: 3A47-A), which has $72 \%$ sequence identity to the target protein, was selected as the template for the target protein sequence for the prediction of the tertiary structure of target protein.

\section{Alignment of the Target-Template Sequence}

For the sequence alignment of the target protein, $\alpha$-glucosidase and template protein (PDB ID: 3A47-A), multiple sequence alignment (MUSCLE) was employed (27) server. ${ }^{3}$ The ClustalW program from the MUSCLE server was used for the alignment of the target-template sequence.

\section{Homology Modeling}

The amino acid sequence of the target protein in FASTA format was copied and paste in the sequence editor of the

${ }^{2}$ http://www.uniprot.org/.

${ }^{3}$ http://www.ebi.ac.uk/Tools/msa/muscle/.

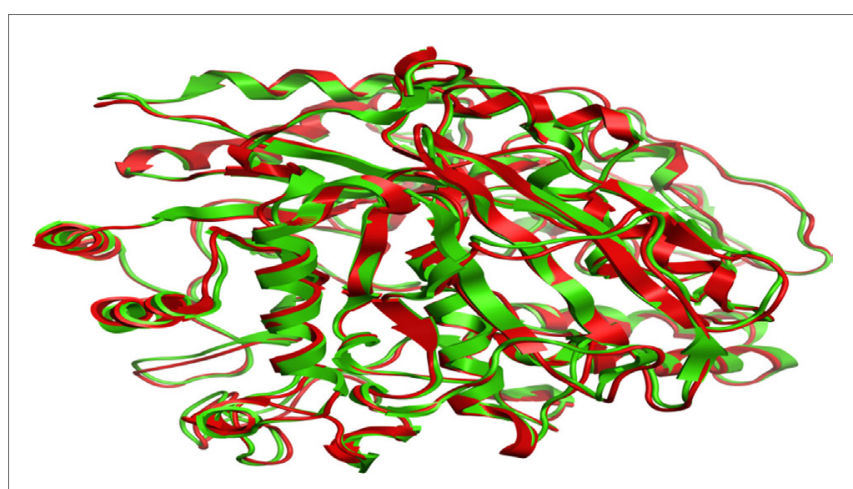

FIGURE 4 | Superposition of target (red) and template (green). 
MOE software. Then, the template protein was loaded in the same MOE software. The chain 1 showed the target protein sequence, and chain 2 showed the template protein sequence. The target and template sequences were aligned before starting the homology modeling and calculated the root mean square deviation (RMSD) with the template. In model refining tool, the intermediate was set to medium, final model to medium, by means of scoring function generalized born/ volume integral (GB/VI). Amber 99 with Solvation RField was used as a force field. Various 10 models were formulated, while the final refine model was introduced to MOE main window.

\section{Validation of Modeled Structure}

The overall geometric and stereochemical qualities of the final model were examined using RAMPAGE and ERRAT server $(28,29)$. ERRAT server was used to check the quality.

\section{Active Site Prediction}

The $\alpha$-glucosidase protein active sites were studied by means of the "MOE-Site Finder" Module, which computes the possible recognition sites from the $3 \mathrm{D}$ atomic coordinates of the protein. The Site Finder module is considered a geometric method, as energy models were not utilized. Rather, the relative positions and accessibility of the protein atoms were targeted followed by

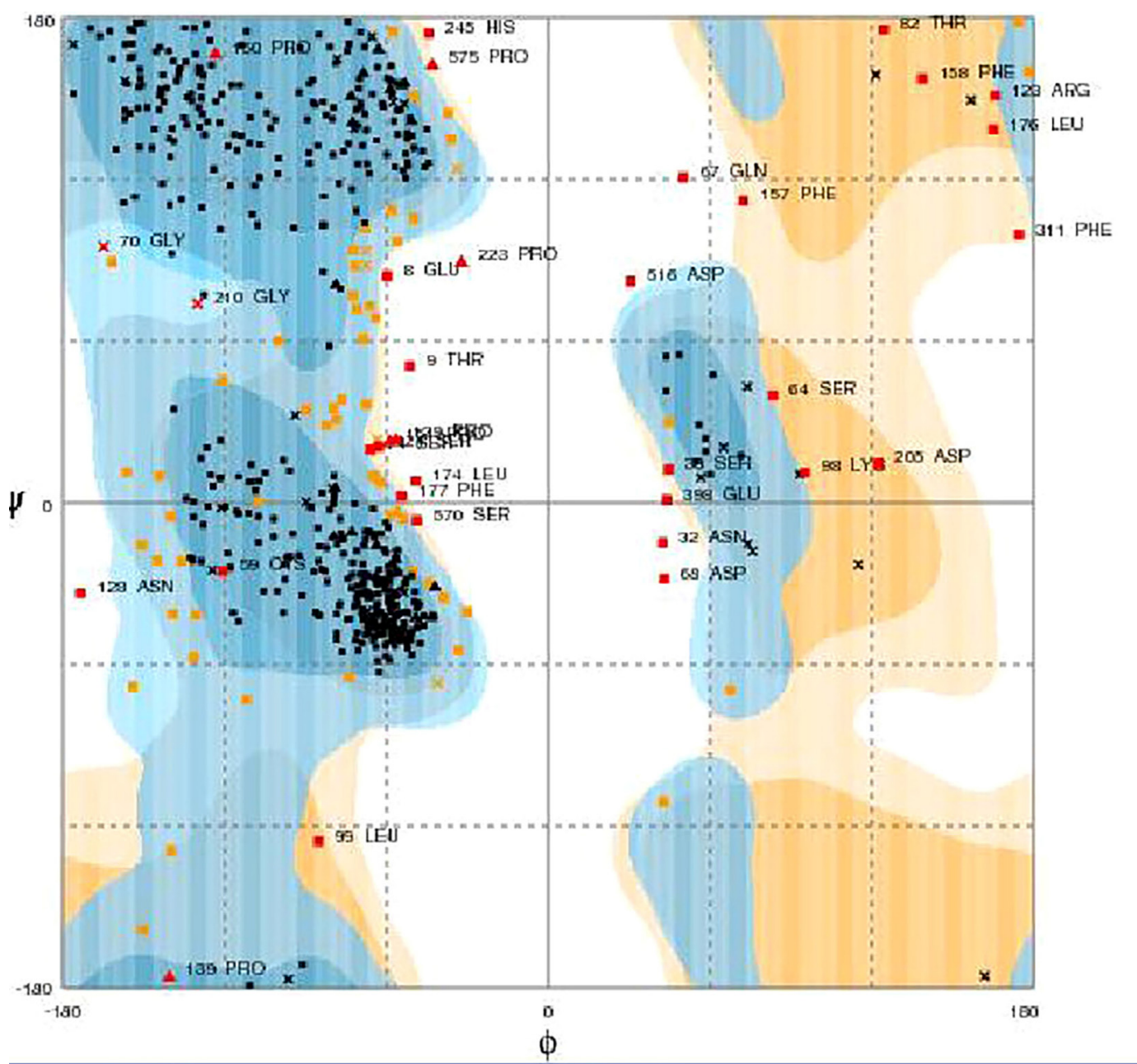

- Aeneralifro-FralFroline Favourad

$\times$

Glycine Favoured
General/Fre.Fro/Proline Allowed

Glycine Allowed

FIGURE 5 | Ramachandran maps of $\boldsymbol{\alpha}$-glucosidase produced by RAMPAGE. Light orange and light blue are allowed regions, while dark orange and dark blue are favored regions. 
a rough classification of chemical types. Once these regions were calculated, dummy atoms were assigned to these sites and later used to make the molecular docking calculation for specified sites.

\section{Ligand Preparation}

The compounds included in our study were all collected from reported literature $(12,23)$. All these compounds were generated by using the Chembio-Office 2010-2012 and then all these compounds were saved in mol file for the purpose to open these files in MOE and were energy minimized via MOE using default parameters.

\section{Protein Preparation}

The modeled structure of the target protein was 3D protonated and then energy minimization was performed by using the MOE software with default parameters.

\section{Molecular Docking}

Molecular docking was performed via MOE-dock with most of the default tools with the aim to find the binding interaction of the ligand with the target protein. Ligand was docked into the target site of predicted homology model of the $\alpha$-glucosidase by mean of MOE-Dock module (v.2011.10), for each ligand 10 conformations were generated. The top-ranked conformation of each ligand was used for detailed study of binding mode.

\section{RESULTS}

\section{Calculation of Physiochemical Properties}

For calculating the physiochemical properties, we used the Expasy-ProtParam server tool. The protein has 584 numbers of amino acids, and its estimated molecular weight was $68,183.3 \mathrm{Da}$ and Theoretical pI: 5.53. The extinction coefficient (EC) of the predicted model was 148,990 at $280 \mathrm{~nm}$, which indicated that at a specific wavelength, how much light was absorbed, EC is in units of $\mathrm{m} \mathrm{cm}^{-1}$, measured in water at $280 \mathrm{~nm}$. The instability index (II) was computed to be 30.07 , which showed the protein was stable. The II more than 40 rated protein as not stable. The hydrophilic character was calculated by the grand average of the hydropathy index value of -0.676 , and the aliphatic index was calculated to be 64.28.

\section{Target-Template Alignment}

The MUSCLE server was used for the determination of the alignment of the query sequence to the template. The alignment was made in order for the development of a resulting model. The configuration is presented in Figure 1. In the figure, $\left(^{*}\right)$ symbol represents the single entire conserved residues, (-) symbol represents the deleted regions, and (:) and (:) symbols represent

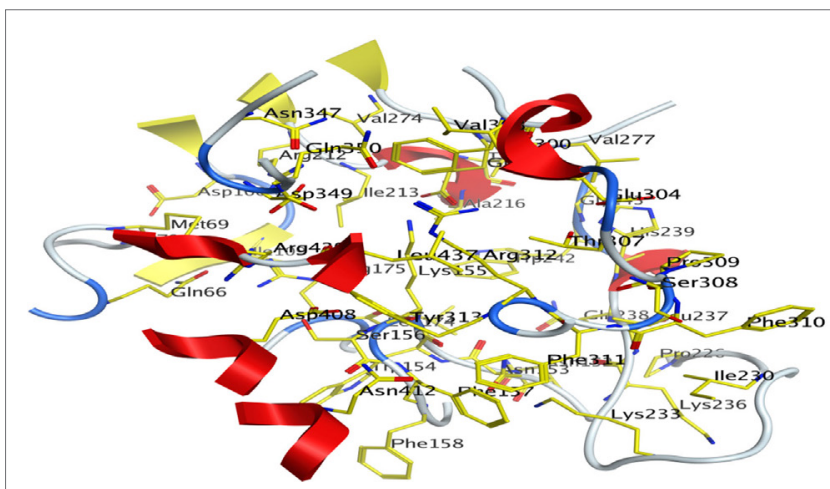

FIGURE 7 | Predicted binding pocket of $\alpha$-glucosidase by mean of Molecular Operating Environment Site Finder.

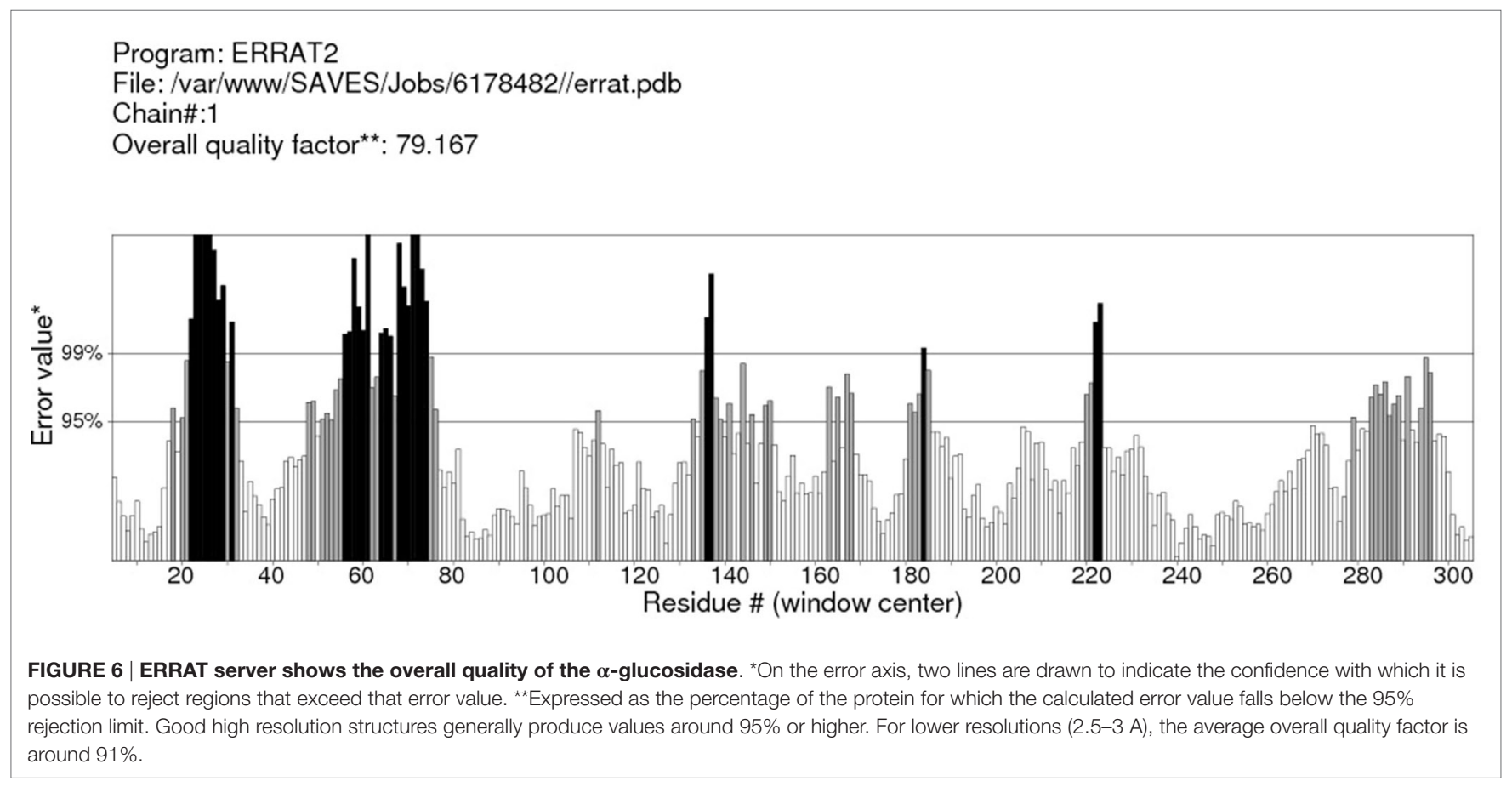


the conservation of strong and weak groups correspondingly. Finally, from the evaluation of the results of target-template alignment, it was found that there is sequence homology between $\alpha$-glucosidase and crystal structure of Isomaltase from S. cerevisiae 3A47-A.

\section{Homology Modeling}

For 3D structure modeling, MOE software (MOE 2010-2011) was employed, while used relative protein structure modeling in the following way.

(1) MOE docked the initial partial geometry of target sequence using template structure and used to preserved residue identity.

(2) The residues without specific backbone coordinates were characterized via a specific logic insertions and deletions treatment (30).

(3) First, a random order was used for loops modeling. A file of probable candidates were scrutinized using contact energy function based on Boltzmann weighted averaging $(31,32)$.

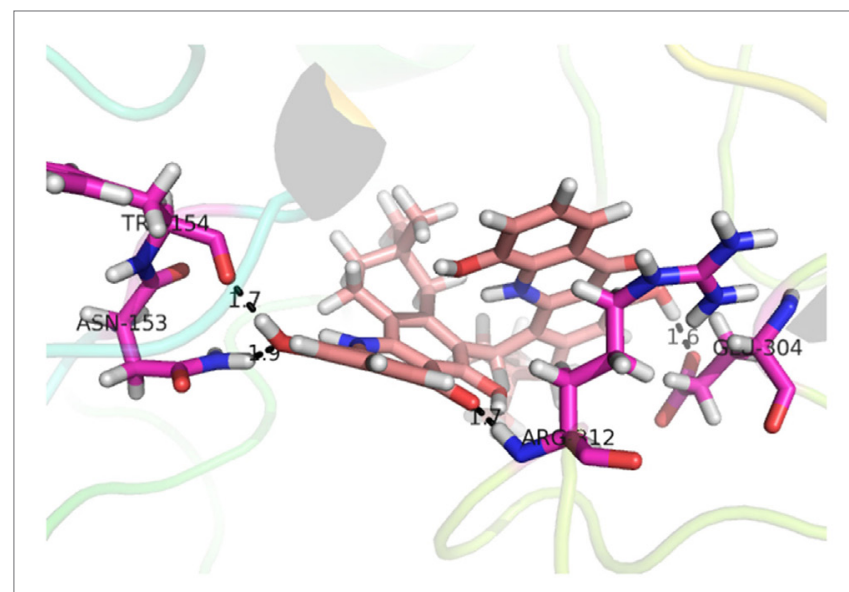

FIGURE 8 | 3D interaction image of most active ligand 17.

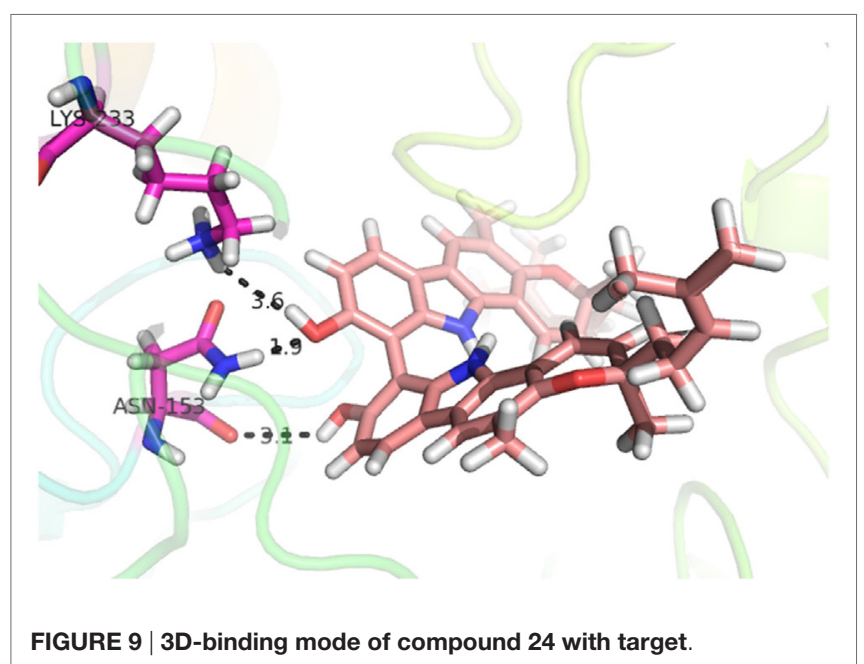

Model was developed while using various tools such as Model Scoring to GB/VI test (33). Force fields to Amber99 used in MOE suggested for protein homology purposes (34). Subsequent to homology modeling, the force field AMBER99 was used to minimize the energy of target structure to $0.05 \mathrm{G}$ and this specifically characterized proteins and nucleic acids. The PDB format was used for resulting structure (Figure 2) having an appropriate identity. The model proposed was superimposed on template structure holding RMSD of 0.639 observing close homology (Figure 3) using the MOE software. The superposition of the target and template are shown in Figure 4.

\section{Validation of Modeled Structure}

RAMPAGE server explained the stereochemical characters of the 3D structure. Stereochemical evaluation of backbone Phi and Psi dihedral angles (35) is shown in Figure 5. Besides, Ramachandran plot analysis showed that $83.8 \%$ components were in the favored region, $10.3 \%$ residue in the permissible region, while $5.8 \%$ residues in the outlier regions of Ramachandran plot, which indicated that the proposed model is reliable for further
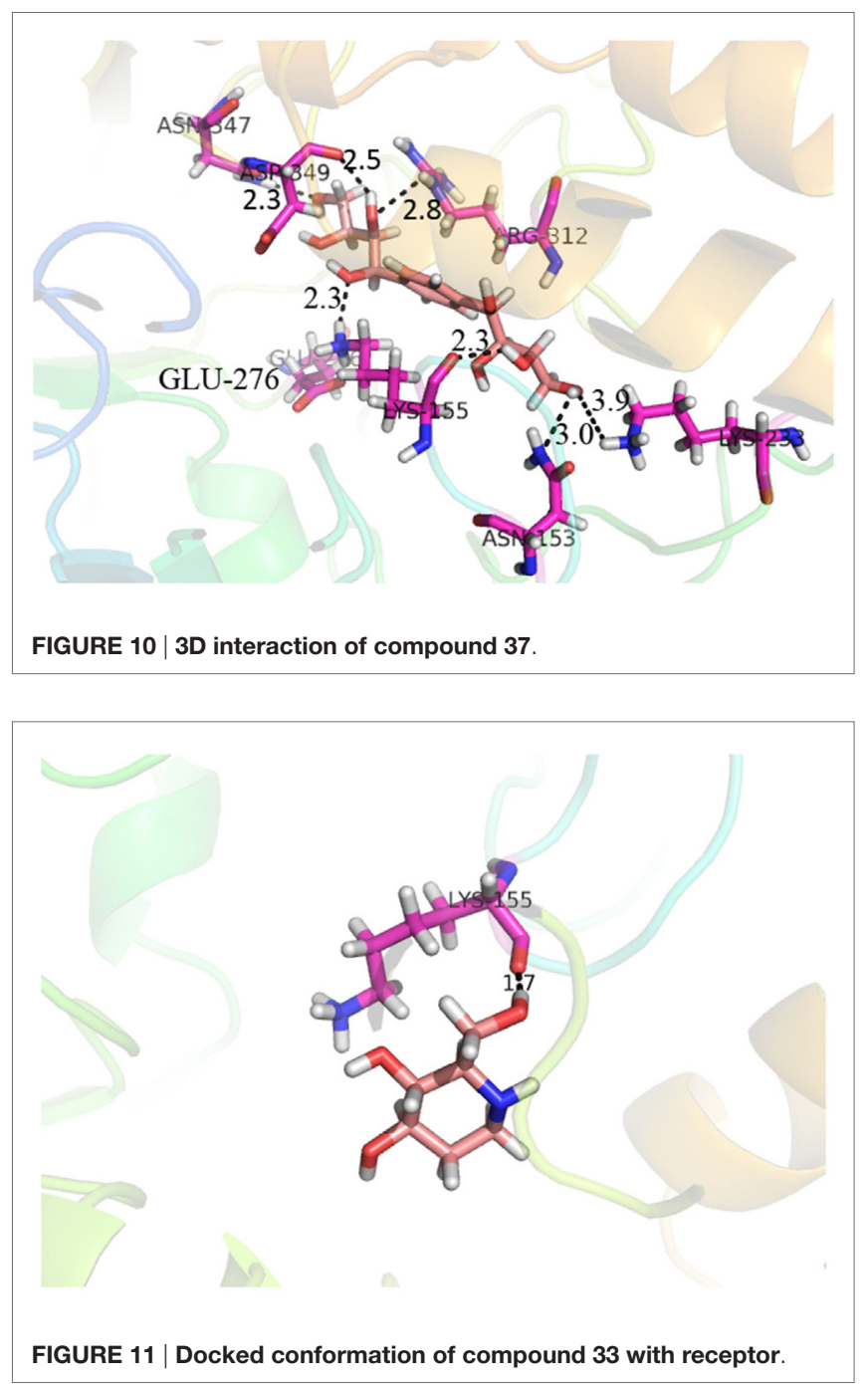
studies. The ERRAT server explained the statistics of non-bonded interaction between different atoms, and a score of 50 was generally suitable and for the 3D structure evaluation, the predicted model had quality score 79.167 , which indicated that the model was reliable and stable, as shown in Figure 6.

\section{Active Site Residues}

The Site-Finder Module was utilized for prediction of the ligandbinding site in the predicted model of $\alpha$-glucosidase showed that GLN66, MET69, ASP106, ILE109, ASN152, ASN153, TRP154, LYS155, SER156, PHE157, PHE158, LEU174, ARG175, ARG212, ILE213, THR215, ALA216, PRO226, ILE230, LYS233, LYS236,
LEU237, GLN238, HIS239, TRP242, VAL274, GLU276, VAL277, PHE300, VAL303, GLU304, THR307, SER308, PRO309, PHE310, PHE311, ARG312, TYR313, ASN347, ASP349, GLN350, ASP408, ASN412, LEU437, and ARG439 were found in the binding site of the predicted model of the $\alpha$-glucosidase, as shown in Figure 7.

\section{Binding Interaction of Ligands with Target Receptor}

In our research studies, we used the 37 known alkaloid inhibitor of $\alpha$-glucosidase from the previous literature. These known alkaloid inhibitors were tested and proved experimentally from
A

Phe

(G14)

(Thr

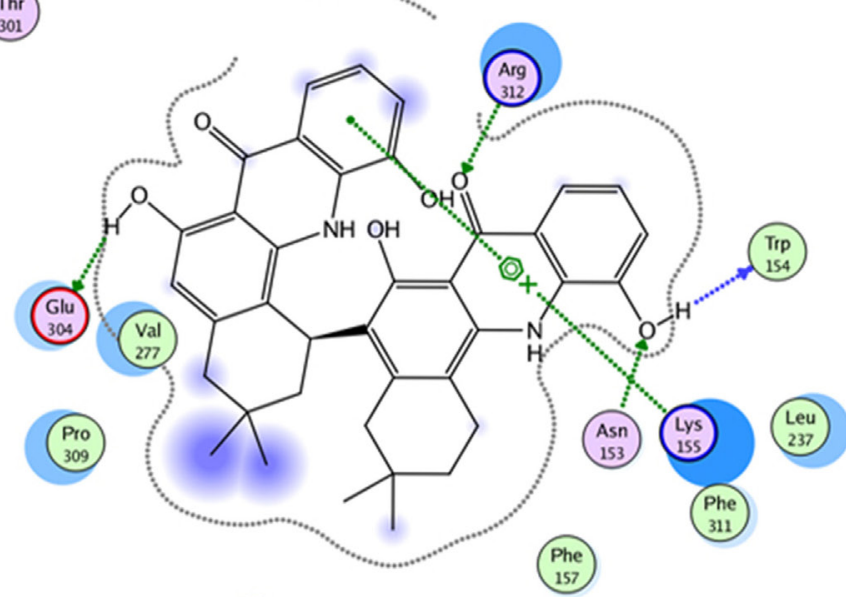

(His

C

(GIn

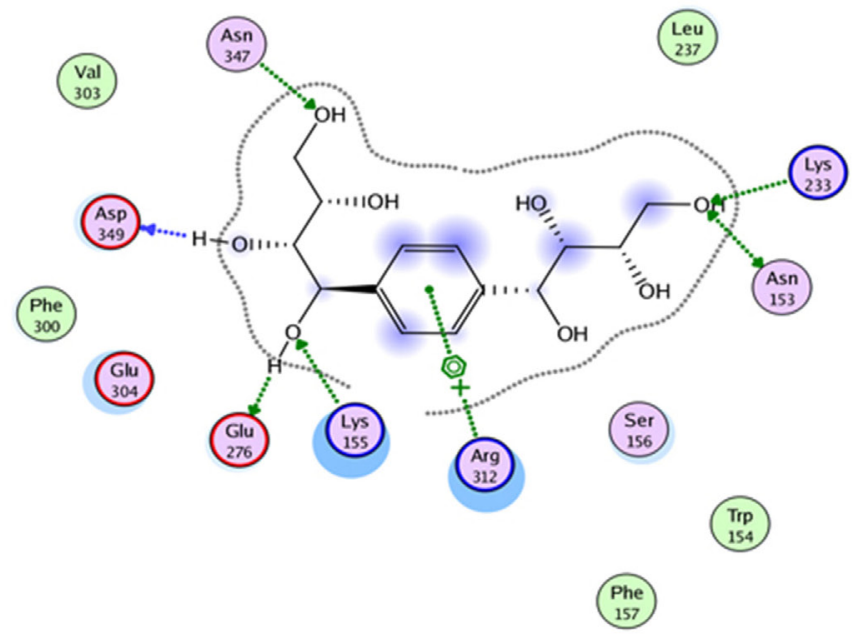

B

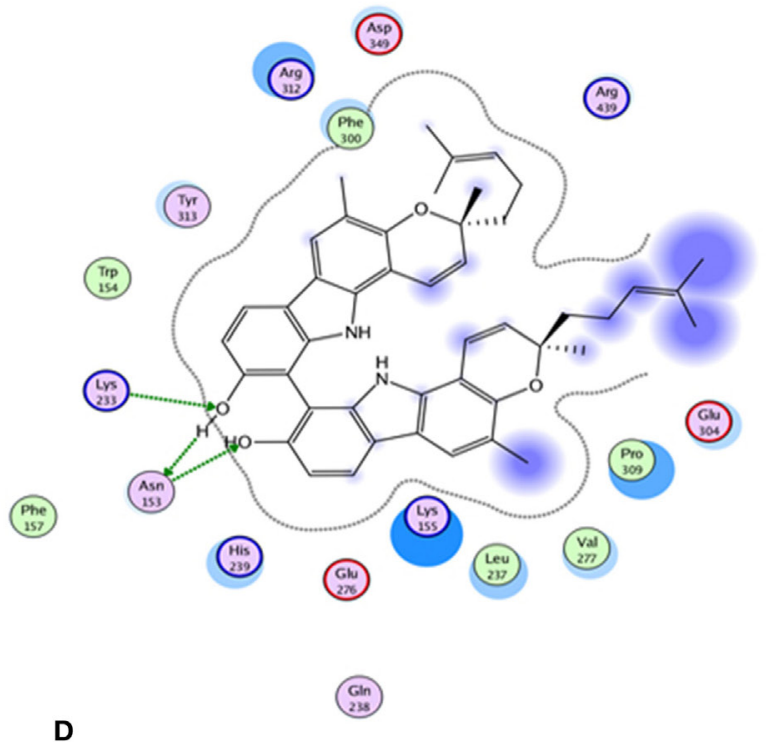

D

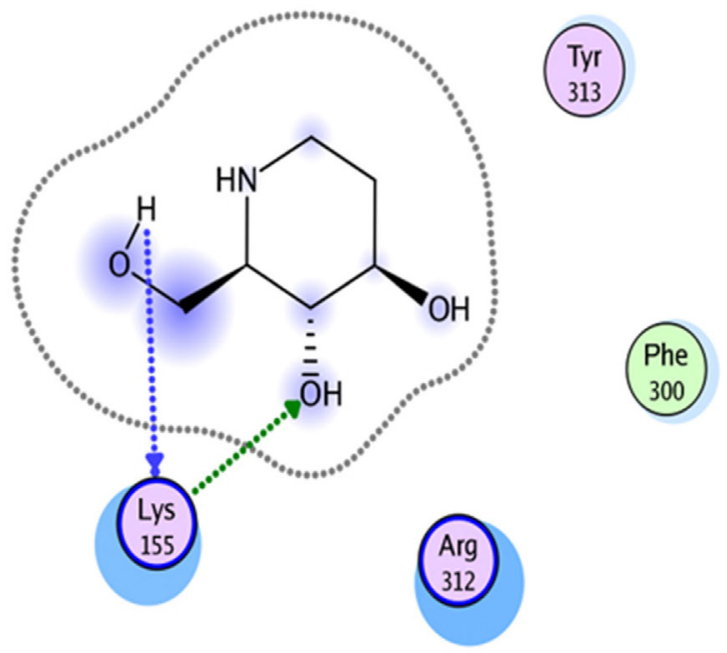

FIGURE 12 | The figure shows the 2D images of the docked conformations of the ligands with the active residues (A) 2D image of compound 17, (B) 2D image of compound 24, (C) 2D image of compound 37, and (D) 2D image of compound 33. 
the previous literature $(12,23)$. In the present research work, we found out the binding interaction and docking scores of these selected compounds with the target protein by molecular docking, as shown in Table 1. These results might be beneficial in the drug designing of the novel and potent inhibitors of the glucosidase.

\section{DISCUSSION}

Compound $\mathbf{1 7}$ and compound $\mathbf{2 4}$ showed the best docking score i.e., -15.1310 and -14.9192 , respectively, among the 37 different alkaloids, and these compounds have good inhibition and docking score nearly similar relative to the reference (standard) ligands, miglitol (-15.4423) and acarbose (-14.7983). These two compounds are most active and showed good interaction with the target protein.

Compound 17, the most active ligand, formed three hydrogen bonds, one hydrophobic interaction, and one arene cation interaction with the Asn153, Arg312, Glu304, Trp154, and Lys155 active amino acid residues, respectively. Lys 155 formed an arene cation interaction with the benzene ring of the phenol moiety of the ligand. Glu304 was observed making a hydrogen bond with the hydrogen atom of the $\mathrm{OH}$ group of another phenol group of the same ligand. Arg312 and Asn153 formed hydrogen bonds with the oxygen atom double bonded with the piperidine moiety of the ligand and oxygen atom of $-\mathrm{OH}$ moiety of the phenol of dihydroxy-3,3-dimethyl-1,2,3,4-tetrahydrobenzo[c]acridin$7(12 \mathrm{H})$-one, respectively, of the same inhibitor. Trp154 showed a hydrophobic interaction with the $\mathrm{H}$ atom of the $-\mathrm{OH}$ group of the dihydroxy-3,3-dimethyl-1,2,3,4-tetrahydrobenzo[c]acridin$7(12 \mathrm{H})$-one moiety. The $3 \mathrm{D}$ interaction of the ligand with receptor was shown in Figure 8. Similarly, these results were in absoulte agreement with the in vitro $\alpha$-glucisade inhibitory activity already reported. Moreover, it also caused marked free radical scavenging effect (20). Compound $\mathbf{2 4}$ is the second most active ligand and interacted with the Asn153 and Lys233 and was observed making three hydrogen bonds. Asn 153 formed H-bonds with the hydrogen atom of $\mathrm{OH}$ group and with the oxygen atom of another $-\mathrm{OH}$ group of the same ligand. Lys233 was observed making an $\mathrm{H}$-bond (hydrogen bond) with the $-\mathrm{O}$ atom (oxygen atom) of the hydroxyl moiety of the inhibitor, as shown in Figure 9. The docking results are consistant with the in vitro $\alpha$-glucisade inhibitory activity already reported, agumented by its comprehensive antioxidant effects (23).

Compound 37 has moderate good docking score -10.4884 and have the best interaction with active residues. It formed five

\section{REFERENCES}

1. Bruni C, Sica V, Auricchio F, Covelli I. Further kinetic and structural characterization of the lysosomal $\alpha$-D-glucoside glucohydrolase from cattle liver. Biochim Biophys Acta (1970) 212(3):470-7. doi:10.1016/0005-2744(70)90253-6

2. Flanagan PR, Forstner GG. Purification of rat intestinal maltase/glucoamylase and its anomalous dissociation either by heat or by low pH. Biochem J (1978) 173:553-63. doi:10.1042/bj1730553

3. Sivakami S, Radhakrishnan A. Purification of rabbit intestinal glucoamylase by affinity chromatography on Sephadex G-200. Indian J Biochem Biophys (1973) 10(4):283 hydrogen bonds with the Asn153, Lys155, Lys233, Glu276, and Asn347, a hydrophobic interaction with the Asp349 and arene cation interaction with the Arg312. Arg312 made an arene cation interaction with the phenylene moiety of the ligand. Lys155 and Glu276 formed hydrogen bonds with the oxygen atom and hydrogen atom of the butane-1-ol. Asn153, Asn347, and Lys233 formed hydrogen bond interactions with the oxygen atom of the hydroxyl group $(-\mathrm{OH})$ of the butane-4-ol. Asp349 formed ahydrophobic interaction with the hydrogen atom of the $-\mathrm{OH}$ group of the butane-2-ol moiety of 1,1'-(1,4-phenylene)-bis(butane-1,2,3,4tetraol) shown in Figure 10.

Compound 33 had low docking score -5.8070 and showed a low number of interaction with the active residues, i.e., formed one hydrogen bond and one hydrophobic interaction with the Lys155, as given in Figure 11. Lys155 made a hydrogen bond with the oxygen atom of $\mathrm{OH}$ group, and Lys 155 interacted with the hydrogen atom of another $-\mathrm{OH}$ moiety of the $(2 \mathrm{R}, 3 \mathrm{R}, 4 \mathrm{R})$ 2-(hydroxymethyl)piperidine-3,4-diol. Figure 12 showed the two-dimensional interaction images of the compounds with the target protein.

\section{CONCLUSION}

The molecular docking was made to recognize the binding interactions of these reported compounds with the receptor. We examined the interaction of inhibitors to that of our target receptor. The molecular docking study indicates good docking score and binding mode and thus showed therapeutic potential of these compounds on $\alpha$-glucosidase inhibition. Compound $\mathbf{1 7}$ (oriciacridone F) and 24 (O-methylmahanine) demonstrated marked interaction with active site residues, which are also correlated with the reported $\mathrm{IC}_{50}$ values and, thus, might be the best candidates for the discovery of novel $\alpha$-glucosidase inhibitors, after in vivo efficacy, safety, and clinical studies.

Moreover, the rest of alkaloids with good receptor interaction could be lead compounds and therefore need further studies in terms of synthesis, structural relationship activity followed by testing in various in vitro and in vivo testing.

\section{AUTHOR CONTRIBUTIONS}

$\mathrm{MZ}, \mathrm{AK}$, and $\mathrm{ML}$ carried out the in silico studies and initial draft of the manuscript. AR assisted in molecular docking of test compounds. HK supervised the entire study and finalized the draft.

4. Sorensen SH, Noren O, Sjostrom H, Danielsen EM. Amphiphilic pig intestinal microvillus maltase/glucoamylase. Eur J Biochem (1982) 126(3):559-68. doi:10.1111/j.1432-1033.1982.tb06817.x

5. Kim SD. $\alpha$-Glucosidase inhibitor isolated from coffee. J Microbiol Biotechnol (2015) 25(2):174-7. doi:10.4014/jmb.1411.11057

6. Pervaiz A, Khan R, Anwar F, Kamal MA, Mushtaq G, Khan H. Alkaloids: an emerging antibacterial modality against methicillin resistant Staphylococcus aureus. Curr Pharm Des (2016) 22(28):4420-9. doi:10.2174/1381612822999 160629115627

7. Rehman S, Khan H. Advances in antioxidant potential of natural alkaloids. Curr Bioact Comp (2016) 12. doi:10.2174/1573407212666160614075157 
8. Pervez S, Khan H, Pervaiz A. Plant alkaloids as an emerging therapeutic alternative for the treatment of depression. Front Pharmacol (2016) 7:28. doi:10.3389/fphar.2016.00028

9. Marya KH. Anti-inflammatory potential of alkaloids as a promising therapeutic modality. Lett Drug Design Discov (2016) 13. doi:10.2174/157018081 3666160712224752

10. Ain Q, Khan H, Mubarak M, Pervaiz A. Plant alkaloids as antiplatelet agent: drugs of future in the light of recent development. Front Pharmacol (2016) 7:292. doi:10.3389/fphar.2016.00292

11. Khattak S, Khan H. Anti-cancer potential of phyto-alkaloids: a prospective review. Curr Cancer Ther Rev (2016) 12(1):66-75. doi:10.2174/1573394712 666160617081638

12. Yin Z, Zhang W, Feng F, Zhang Y, Kang W. $\alpha$-Glucosidase inhibitors isolated from medicinal plants. Food Sci Human Wellness (2014) 3(3):136-74. doi:10.1016/j.fshw.2014.11.003

13. Gao H, Huang Y-N, Gao B, Li P, Inagaki C, Kawabata J. Inhibitory effect on $\alpha$-glucosidase by Adhatoda vasica Nees. Food Chem (2008) 108(3):965-72. doi:10.1016/j.foodchem.2007.12.002

14. Ikeda K, Takahashi M, Nishida M, Miyauchi M, Kizu H, Kameda Y, et al. Homonojirimycin analogues and their glucosides from Lobelia sessilifolia and Adenophora spp. (Campanulaceae). Carbohydr Res (1999) 323(1):73-80. doi:10.1016/S0008-6215(99)00246-3

15. Tabopda TK, Ngoupayo J, Awoussong PK, Mitaine-Offer A-C, Ali MS, Ngadjui BT, et al. Triprenylated flavonoids from Dorstenia psilurus and their $\alpha$-glucosidase inhibition properties. J Nat Prod (2008) 71(12):2068-72. doi:10.1021/np800509u

16. Xiangrui YHZ. Research progress of 1-deoxynojirimycin. Bull Seric (2003) $1: 22-9$.

17. MA J, LIU S-X. Research progress of DNJ in mulberry twig. Food Sci Technol (2006) 9:052.

18. Shibano M, Kakutani K, Taniguchi M, Yasuda M, Baba K. Antioxidant constituents in the dayflower (Commelina communis L.) and their $\alpha$-glucosidaseinhibitory activity. J Nat Med (2008) 62(3):349-53. doi:10.1007/s11418008-0244-1

19. Tabopda TK, Ngoupayo J, Liu J, Mitaine-Offer A-C, Tanoli SAK, Khan SN, et al. Bioactive aristolactams from Piper umbellatum. Phytochemistry (2008) 69(8):1726-31. doi:10.1016/j.phytochem.2008.02.018

20. Wansi JD, Wandji J, Mbaze Meva'a L, Kamdem Waffo AF, Ranjit R, Khan SN, et al. Alpha-glucosidase inhibitory and antioxidant acridone alkaloids from the stem bark of Oriciopsis glaberrima ENGL. (Rutaceae). Chem Pharm Bull (Tokyo) (2006) 54(3):292-6. doi:10.1248/cpb.54.292

21. Kim S-D. $\alpha$-Glucosidase inhibitor from Buthus martensii Karsch. Food Chem (2013) 136(2):297-300. doi:10.1016/j.foodchem.2012.08.063

22. Damsud T, Adisakwattana S, Phuwapraisirisan P. Three new phenylpropanoyl amides from the leaves of Piper sarmentosum and their $\alpha$-glucosidase inhibitory activities. Phytochem Lett (2013) 6(3):350-4. doi:10.1016/j.phytol.2013.04.001

23. Uvarani C, Jaivel N, Sankaran M, Chandraprakash K, Ata A, Mohan PS. Axially chiral biscarbazoles and biological evaluation of the constituents from Murraya koenigii. Fitoterapia (2014) 94:10-20. doi:10.1016/j.fitote.2014.01.004
24. Tabussum A, Riaz N, Saleem M, Ashraf M, Ahmad M, Alam U, et al. $\alpha$-Glucosidase inhibitory constituents from Chrozophora plicata. Phytochem Lett (2013) 6(4):614-9. doi:10.1016/j.phytol.2013.08.005

25. Berman HM, Westbrook J, Feng Z, Gilliland G, Bhat T, Weissig H, et al. The protein data bank. Nucleic Acids Res (2000) 28(1):235-42. doi:10.1093/ nar/28.1.235

26. Altschul SF, Madden TL, Schäffer AA, Zhang J, Zhang Z, Miller W, et al. Gapped BLAST and PSI-BLAST: a new generation of protein database search programs. Nucleic Acids Res (1997) 25(17):3389-402. doi:10.1093/ nar/25.17.3389

27. Edgar RC. MUSCLE: multiple sequence alignment with high accuracy and high throughput. Nucleic Acids Res (2004) 32(5):1792-7. doi:10.1093/nar/ gkh340

28. Lovell SC, Davis IW, Arendall WB, de Bakker PI, Word JM, Prisant MG, et al. Structure validation by $\mathrm{C} \alpha$ geometry: $\phi, \psi$ and $\mathrm{C} \beta$ deviation. Proteins (2003) 50(3):437-50. doi:10.1002/prot.10286

29. Colovos C, Yeates TO. Verification of protein structures: patterns of nonbonded atomic interactions. Protein Sci (1993) 2(9):1511-9. doi:10.1002/ pro. 5560020916

30. Needleman SB, Wunsch CD. A general method applicable to the search for similarities in the amino acid sequence of two proteins. J Mol Biol (1970) 48(3):443-53. doi:10.1016/0022-2836(70)90057-4

31. Sippl MJ. Boltzmann's principle, knowledge-based mean fields and protein folding. An approach to the computational determination of protein structures. J Comput Aided Mol Des (1993) 7(4):473-501. doi:10.1007/BF02337562

32. Sippl MJ. Recognition of errors in three-dimensional structures of proteins. Proteins (1993) 17(4):355-62. doi:10.1002/prot.340170404

33. Labute $\mathrm{P}$. The generalized born/volume integral implicit solvent model: estimation of the free energy of hydration using London dispersion instead of atomic surface area. J Comput Chem (2008) 29(10):1693-8. doi:10.1002/ jcc. 20933

34. Summa CM, Levitt M. Near-native structure refinement using in vacuo energy minimization. Proc Natl Acad Sci U S A (2007) 104(9):3177-82. doi:10.1073/ pnas.0611593104

35. Lovell S, Davis I, Adrendall W, de Bakker P, Word J, Prisant M, et al. Structure validation by $\mathrm{C}$ alpha geometry: 18 phi, psi and $\mathrm{C}$ beta deviation. Proteins (2003) 50:437-50. doi:10.1002/prot.10286

Conflict of Interest Statement: The authors declare that the research was conducted in the absence of any commercial or financial relationships that could be construed as a potential conflict of interest.

Copyright (c) 2016 Zafar, Khan, Rauf, Khan and Lodhi. This is an open-access article distributed under the terms of the Creative Commons Attribution License (CC BY). The use, distribution or reproduction in other forums is permitted, provided the original author(s) or licensor are credited and that the original publication in this journal is cited, in accordance with accepted academic practice. No use, distribution or reproduction is permitted which does not comply with these terms. 